\title{
Social inclusion and valued roles: a supportive framework
}

\begin{abstract}
The aim of this paper is to examine the concepts of social exclusion, social inclusion and their relevance to health, well-being and valued social roles. The article presents a framework, based on Social Role Valorization (SRV), which was developed initially to support and sustain socially valued roles for those who are, or are at risk of, being devalued within our society. The framework incorporates these principles and can be used by health professionals across a range of practice, as a legitimate starting point from which to support the acquisition of socially valued roles which are integral to inclusion.
\end{abstract}

\section{8 words}

\section{Introduction}

There are a number of individuals who are marginalised within society due to a variety of reasons, one of which is disability, and as a result are prevented from participating in everyday life. The World Health Organisation's (WHO) (2001) International Classification of Functioning, Disability and Health has defined disability as

"the outcome or result of a complex relationship between an individual's health condition and personal factors, and of the external factors that represent the circumstances in which the individual lives" (www.who.int/classifications/icf).

This change in definition demonstrates a shift from the medical model of disability to the social model, where the inability to be integrated into society lies not with the individual themselves, but on the barriers caused by structures, policies and practices prevalent in society (Ware et al, 2007).

In 1995 the UK government, through the publication of the Disability Discrimination Act, made it unlawful to discriminate against individuals who have a disability, and thereby promote social inclusion. To eliminate discrimination, the 
Disability Rights Commission was established in 2000, and provided a mechanism to offer information to relevant individuals and agencies, to establish codes of practice and ensure these were adhered to, and to act as arbitrator in cases where disputes involving potential discrimination arose (Smith and Keenan, 2004).

Social Role Valorization (Wolfensberger, 1980) is considered to be a means of supporting the development and maintenance of socially valued roles by the use of culturally valued means to ensure that people have the same living conditions that are at least equivalent to the average citizen.Health care professionals may be considered as well placed to identify the potential for this to happen within their client group, and may be able to minimise or reduce the potential for those individuals to maintain social inclusion. In tackling the root causes of exclusion, which has been associated with either maximizing ill health or as a direct result of this, it would be hoped that social inclusion could be engendered (Burnett and Peel, 2001), leading to improved health and wellbeing.

\section{Social exclusion}

A report published by Levitas et al (2007, p 9) defined social exclusion as:

"a complex and multi-dimensional process. It involves the lack or denial of resources, rights, goods and services, and the inability to participate in the normal relationships and activities, available to the majority of people in a society, whether in economic, social, cultural or political arenas. It affects both the quality of life of individuals and the equity and cohesion of society as a whole".

In essence, social exclusion is a process whereby individuals or groups are partially or wholly excluded from full participation in the life of their community.

In 1997, the Social Exclusion unit was commissioned in the UK with the remit of tackling the causes of social exclusion and promoting inclusion of the most disadvantaged within society. Through the early identification of potential 
problems that result in social exclusion, the government aims to demonstrate that by providing support and preventative mechanisms, positive change is possible. The need to tackle social exclusion has also been recognised at European level as recognised in the Joint Report of Social Protection and Social Inclusion 2008 (http://ec.europa.eu/employment) which states that health inequalities negatively affect the most vulnerable groups in society and that poor health contributes towards social exclusion and loss of human and economic potential. The European Union has produced national actions plans such as the use of universal design to make environments, products, communication systems and services usable by all yet avoiding solutions that could lead to stigma and separation (https://wcd.coe.int). Similarly, social enterprise brings like minded business together for the good of the whole community. In its social enterprise action plan, Scaling New Heights (DH 2006) the UK government recognises the value to society of reinvesting capital by businesses who are interested in the development of the community rather than being driven by profit. It establishes several ways of how this will be achieved, including providing advice and support to businesses, overcoming barriers regarding finance and resource implications and encouraging social enterprises to work collaboratively with government departments.

\section{Social inclusion}

Social inclusion could be seen as an ideal that modern society aspires to, however it has been considered as a difficult concept to define, which may be due in part to the multifaceted nature of the reasons why individuals are excluded from society (Wilcock 2006). Social inclusion is linked to the concept of equal opportunity, the individual is part of a social community where they were educated, raised and employed which is felt to engender feelings of belonging, trust and unity (Westwood 2003). If this does not occur, the individual can experience marginalisation, alienation and distrust. In contrast to social exclusion, inclusion exists where people are enabled to take part in the activities and roles that are part of mainstream society such as having a job (Wistow and 
Schneider 2003), visiting the local leisure facilities and taking part in family life. Inclusion is concerned with being able to access and utilise mainstream services and to be included fully in the life of the local community (DH, 2001)

The Quality Assurance Agency (QAA) is responsible for the delivery of Allied Health Programmes in Higher Education Institutes within the UK and has recognised the need for socially inclusive practice. The agency has developed benchmark statements as 'authoritative reference points' (QAA 2001, p11) to ensure the undergraduate curriculum enables future health care professionals to be fit for practice, and registration with the Health Professional Council is a statutory prerequisite for practice (www.hpc.uk, 2005). The benchmark statements clearly state that those eligible to practice should "contribute to the promotion of social inclusion" (wwwqaa.ac.uk, 2001). In a similar vein, the Capabilities for Inclusive Practice" (DH, 2007) make reference to the Ten Essential Shared Capabilities (Table 1) which states that issues of discrimination, exclusion and the maintenance of valued social roles for services users should be core components of the curriculum for all professional and non professional staff including the allied health professions.

Table 1

\begin{tabular}{|l|l|}
\hline $\begin{array}{l}\text { The Ten Essential Shared Capacities - A framework for the whole of the Mental } \\
\text { Health Workforce }\end{array}$ \\
\hline 1 & $\begin{array}{l}\text { Working in partnership with service users, families, carers and the } \\
\text { wider community }\end{array}$ \\
\hline 2 & $\begin{array}{l}\text { Respecting and valuing diversity including age, race, disability, culture } \\
\text { and sexuality }\end{array}$ \\
\hline 3 & $\begin{array}{l}\text { Ethical practice that respects rights and aspirations, providing } \\
\text { services within professional, legal and local boundaries }\end{array}$ \\
\hline 4 & $\begin{array}{l}\text { Challenge inequality that includes stigma, discrimination and } \\
\text { exclusion to create, develop and maintain valued social roles in local } \\
\text { communities }\end{array}$ \\
\hline 6 & $\begin{array}{l}\text { Promote recovery to support people to tackle mental health issues } \\
\text { and work towards a valued lifestyle }\end{array}$ \\
\hline 7 & $\begin{array}{l}\text { Identify peoples strengths and needs alongside their preferred lifestyle } \\
\text { and aspirations }\end{array}$ \\
\hline Provide care that is centred on the service user
\end{tabular}




\begin{tabular}{|l|l|}
\hline 8 & $\begin{array}{l}\text { Make a difference, support access to and update of the best quality } \\
\text { and evidence based care }\end{array}$ \\
\hline 9 & Promote safety and positive risk taking via informed choice \\
\hline 10 & $\begin{array}{l}\text { Personal development planning that incorporates up to date life long } \\
\text { learning and persona and professional development }\end{array}$ \\
\hline
\end{tabular}

\section{The importance of social roles and Social Role Valorization Theory}

The concept of valued social roles is considered to be intrinsically linked to the issues of social inclusion and exclusion ( $\mathrm{DH}, 2007)$. It is through roles that people have a place and are seen to have a place in the world. Roles define how people see themselves and how others see them, as well as shaping identity. The roles an individual may hold are likely to affect all aspects of life including relationships, what people do, where they go, routines, habits, services and resources available to them. Role also has a significant impact upon finance, which in turn has an influence upon the individual's physical environment, diet and health and well-being (Race, 1999).

Wolfensberger (1980) developed the concept of Social Role Valorization (SRV) to support the development and maintenance of valued roles for those people in society who are at risk of devaluation. This concept was developed initially for people who have a learning disability but is equally of value for any person who may be at risk of social devaluation including those who have mental health needs, older people and people who have a physical disability.

Race (2003) states that those people who are commonly at risk of devaluation and therefore social exclusion within western society include:

- Those with some form of impairment of body, mind or senses

- Those whose behaviour is considered disordered

- People who are visibly different e.g. very tall, very short

- People who are or represent anti-establishment

- Those who are living below the poverty line 
- Those with low levels of skill

- Those not assimilated into the dominant culture for reasons such as religion, race, age, ethnicity, language, value system, immigrants and migrants.

It is important to note that some people fall into several of these categories and are therefore at risk of discrimination and exclusion on a variety of levels. According to the Government white paper "Valuing people" (DH, 2001) there are still many people who live a life apart from mainstream society and have reduced life opportunities. People at risk of exclusion need to have the same opportunities as other citizens. The drivers for this include increased awareness of moral issues and resultant public intolerance of the growing profile of inequalities faced by people who have a disability in western societies. This is being addressed by emergence of policy and legislation that supports inclusion, the civil rights movement and sociological theories that demonstrate how people who may be at risk of devaluation have the capabilities to live in and make a positive contribution to their community (Race 1999). In addition to this, social exclusion is linked to a poor quality of life and ill-health, issues that are significant on the current UK government agenda (HM Government 2006).

According to the theory of social role valorisation, society will provide benefits to those who hold valued social roles and in reference to Race (1999) the more valued roles a person holds, the more others will tolerate or reinterpret negative roles and characteristics. Significantly valued roles may therefore act as a defence against being devalued.

\section{A Framework against which to review services}

Social role valorisation was underpinned by core service principles that were adapted for the UK by O'Brien and Tyne (1981) in the form of 5 service accomplishments so that service providers have a strategy to operationalise this concept. The framework described within this paper is based on their service 
accomplishments, and incorporates concepts from those more recently proposed by the National Development Team (www.ndt.org.uk), who have developed the "Inclusion Traffic Light System", the Social Inclusion Planner. Ideas suggested in Realising Recovery: A National Framework for Learning and Training in Recovery Focused Practice (2007) have also been included.

The framework suggested within this paper (Table 2) can be used as a starting point from which to review existing services and from which action plans for implementing change can be completed. This may help to promote and support social inclusion and the acquisition of valued social roles within mainstream communities for service users from a diverse variety of settings. Within the following framework, several questions are posed which can be applied to either a service or individual practitioner. Where there are obvious barriers within an area of the framework, an action plan can be developed and priority list drawn up in negotiation with the service user, and their family/carers and service providers (Bates et al., 2006).

Table 2

\begin{tabular}{|l|l|}
\hline \multicolumn{3}{|c|}{ A framework to support inclusion } \\
\hline Service Context & $\begin{array}{l}\text { Current Service / Practice and } \\
\text { Action Plan }\end{array}$ \\
\hline $\begin{array}{l}\text { Community Presence } \\
\text { Do service users live in the same } \\
\text { community as ordinary citizens, for } \\
\text { example live in the same } \\
\text { neighbourhood, work in open } \\
\text { employment, use local shops and local } \\
\text { recreational facilities? }\end{array}$ & \\
\hline $\begin{array}{l}\text { Choice } \\
\text { Are service users supported in making } \\
\text { informed choices that are meaningful to } \\
\text { them and is choice presented on a } \\
\text { range of issues from those that are }\end{array}$ & \\
\hline
\end{tabular}




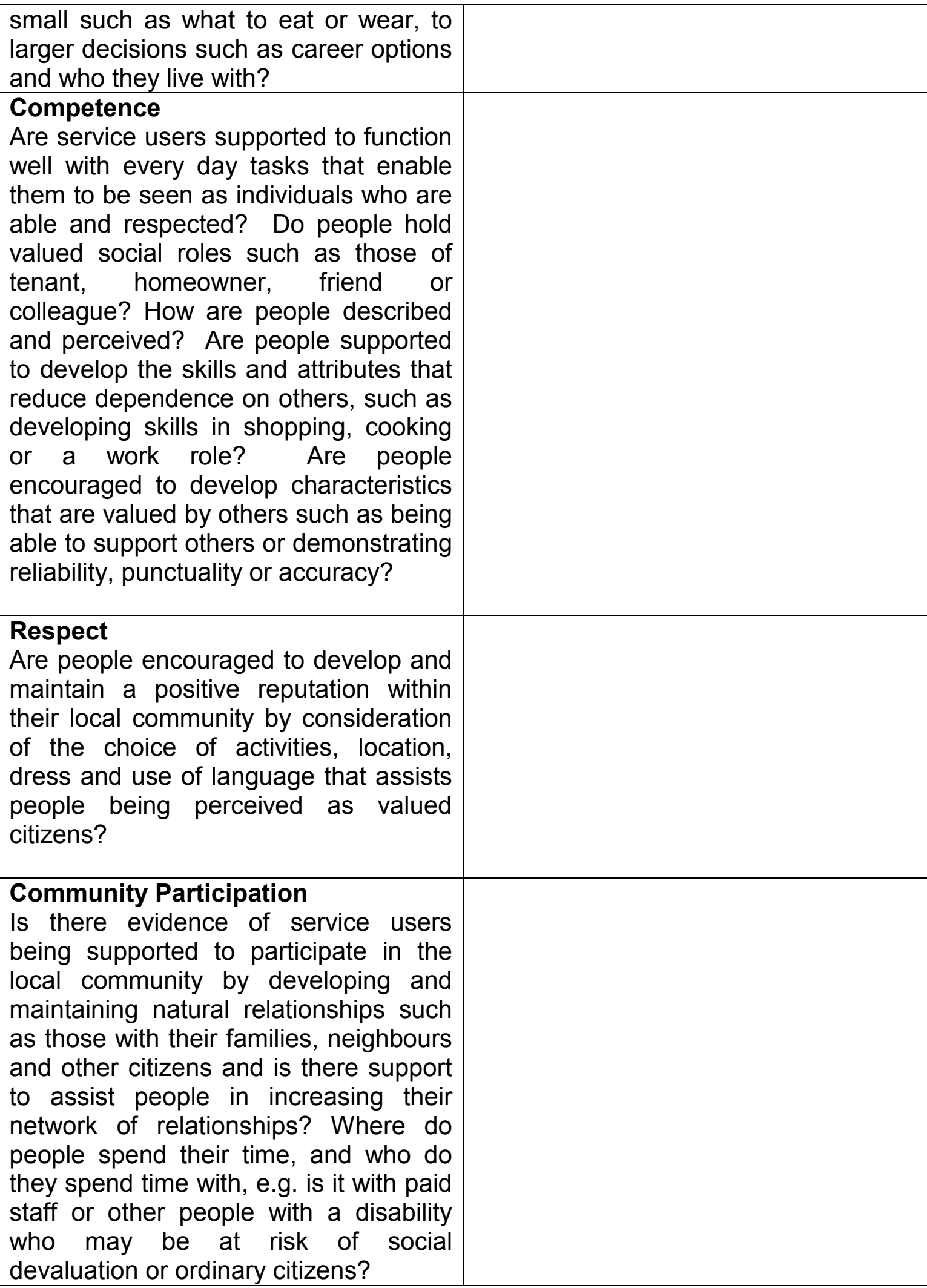




\section{Theoretical and practical challenges}

There are a number of factors that need to be considered as services and individual practitioners strive to implement strategies and practice that supports social inclusion and the acquisition of valued roles, the first being the concept of SRV itself. Social role valorisation grew out of the earlier concept of normalisation and was renamed as people misinterpreted the concept as meaning that people/ service users should fit in with society and appear "normal", that they should present themselves, or behave in a way as other people would. The concept of social role valorization was developed and defined as the use of culturally typical or valued means to support people at risk of devaluation to have the same living conditions and be supported in their experiences, behaviour, status and reputation so that it is at least the same as the average citizen (Wolfensberger, 1980)

One critique of SRV is that the guidelines and principles make assumptions based on sociology and psychology. SRV predicts what is likely to happen to people in given circumstances and can offer practical suggestions (Race, 2003). However, that which is ultimately devalued or valued within a particular culture or cultural sub-set, and decisions regarding how far positive roles are defined and agreed upon, are not based on scientific fact but are culturally and socially determined and are therefore subject to change. Ultimately the question of who should change or accommodate diversity, be this society or individuals who may be at risk of devaluation, is related to the concept of values (Wolfensberger, 1995)

Resources are a common yet very real barrier to social inclusion and the development of valued social roles. One of the most common resource difficulties is that of available finances, and where there is not enough money to provide adequate staffing levels or training. This directly impacts on service users who will either be unable to attend events and activities that would support social inclusion, or they will not have the appropriate type of support to enhance 
inclusion. Additionally, the opportunity to engage in the local community is dependent upon the level and extent of community services that are available to the general public within a given locality ( $\mathrm{DH}, 2007)$. It is also important to note that social inclusion may be more difficult to achieve where people have profound and complex requirements such as those with multiple physical and psychological needs (Atherton, 2003).

A further consideration when using such a framework is that staff, service users and their carers need to understand the purpose and value of social inclusion Having understood this, a Person-Centred Planning approach $(\mathrm{DH}, 2001)$ is then recommended to prioritise areas for development so that the wishes, needs and capabilities of the service user, as well as the demands it will place upon service providers, carers and families are adequately considered ( $\mathrm{DH}, 2007)$. An additional and perhaps unexpected barrier to social inclusion and the acquisition of valued social roles may come from health and social care providers themselves. An example of this was demonstrated by Rosowsky (2005) who found that service providers may hold negative views towards older people and those with mental health problems and learning disability, which could possibly lead to the perpetuation of social devaluation and exclusion.

\section{Supporting social inclusion}

According to Valuing People (2001), the way forward requires a number of initiatives at different levels. The framework outlined within this article can be used as a starting point by service providers/individual practitioners to consider how to promote social inclusion on a practical level. There are however further contextual factors that have wide reaching implications. In the UK, variation and inequality of services across the different regions needs to be redressed and the establishment of effective partnerships and inter-agency co-operation across all sectors including health, social, private and voluntary is required. The need for training is also of consequence so that the workforce is qualified and has the 
skills to meet the needs of service users at both a professional and care staff level. In addition to this, effective joint working that includes greater partnership working with service users themselves and their carers/families utilising a client centred approach should help to promote service user autonomy and choice.

The need for work to be undertaken at different levels is reiterated by the National Development Team (http://www.ndt.org.uk 2007), the London Development Centre for Mental Health (2005), and is summarised by Race (1999) as follows:

- The individual level where strengths, abilities and resources are promoted and maintained

- The environmental level which considers the involvement of other people in the individuals life, the impact of the of the physical environment, and the need for assistance, adaptations and modification

- A societal or systems approach that addresses the education and awareness of both the public and service providers in relation to social values and the need for appropriate legislation, policies and health/social service support systems.

\section{Conclusion}

Social inclusion is currently high on the agenda at both national and international levels. This is evidenced at a number of levels that include the growth of the civil rights movement, changes in public opinion towards discrimination against people who have a disability and the awareness of links between health, wellbeing and social inclusion. Within government policies and legislation, there have been changes within service planning and delivery with a shift towards a more social rather than medical model of care (Ware et al 2007) and the implementation of sociological theories that has demonstrated the ability of those at risk of social exclusion to make a positive contribution to their community.

In order to enhance social inclusion for the many groups of people within society who are at risk of devaluation and therefore exclusion, support must be provided 
for the acquisition and maintenance of valued social roles as expressed within Social Role Valorisation theories. Valued social roles are critical within this process since roles define how people see themselves, how others see them and can affect all areas of life including where people live, their habits, routines, lifestyle and health (Race 1999).

Inclusion is not simply about sharing places within a local community, but is about fully participating in the social function of the community. Social inclusion however is difficult to achieve. It can be relatively easy to support physical integration as in the provision of appropriate housing and furnishings, but to achieve social integration and inclusion is much harder. The existence of a climate of real inclusion and acceptance within our society is arguable and supporting people in the acquisition of socially valued roles and lifestyles that support inclusion still has a long way to go, especially within the development and maintenance of valued relationships (Atherton, 2003). For the health care professions therefore, this is a clear challenge to our practice and highlights the importance of socially valued roles and their significance in supporting social inclusion.

\section{Key Points:}

1) People may be at risk of devaluation and social exclusion because they present in some way as different to most other citizens, because they have low levels of skill or finances or because they are not assimilated into the dominant culture.

2) Social inclusion is important to an individual's health, quality of life and sense of well-being and is considered to be an important issue at national and international level 
3) People at risk of social exclusion need to be supported in the acquisition and maintenance of valued social roles.

4) The practical implementation of Social Role Valorisation Theories are likely to support social inclusion

5) Supporting the development and maintenance of valued roles is an intrinsic role for all health care professionals

\section{References}

Atherton, H. (2003) A History of Learning Disabilities in Gates,B (Ed) Learning Disabilities Towards Inclusion, $4^{\text {th }}$ Edition. London: Churchill Livingstone.

Bates, P., Gee, H., Klingel, U. and Lippmann, W. (2006) Moving to Inclusion. Mental Health Today, 16(8) pp16-18.

Burnett A and Peel M (2001) Health needs of asylum seekers and refugees British Medical Journal, 322 (7285) pp 544-547.

Great Britain, Department of Health (2001) Valuing People: A New Strategy for Learning Disability for the 21st Century. London: HMSO.

Great Britain, Department of Health (2004) The Ten Essential Shared Capabilities - A Framework for the whole of the Mental Health Workforce. London: HMSO.

Great Britain, The Cabinet Office (2006) Reaching Out: An Action Plan on Social Exclusion Report. London: The Cabinet Office. 
Great Britain, Department of Health (2007) Capabilities for Inclusive Practice. London: HMSO.

Great Britain, Department of Health (2007) Scaling New Heights. London: HMSO.

Great Britain, Department of Health (2007) Social Inclusion Planner ans Realising Recovery: A National Framework for Learning and Training in Recovery Focused Practice .London: HMSO.

Levitas, R., Pantazis, C., Fahmy, E., Gordon, D., Lloyd, E. and Patsios, D. (2007) The Multi-Dimensional Analysis of Social Exclusion. Department of Sociology and School for Social Policy, Townsend Centre for the International Study of Poverty and Bristol Institute for Public Affairs, University of Bristol

London Development Centre for Mental Health (2005) Redesigning mental health day services - a modernisation toolkit for London. London: The London Development Centre for Mental Health (CSIP).

O'Brien and Tyne (1981) The principle of normalisation: a foundation for effective services. London: $\mathrm{CMH}$.

Quality Assurance Agency for Higher Education (2001) The framework for higher education qualifications in England, Wales and Northern Ireland. Gloucester: QAA.

Race, D. (1999) Social Role Valorisation and the English Experience. London: Whiting and Birch Ltd.

Race, D. (2003) Leadership and change in human services selected readings from Wolf Wolfensberger (2003) London: Routledge

Rosowsky, E. (2005) Agiesm and Professional Training in Ageing: Who Will be There to Help? Generations. Vol. 29 (3), pp55-58.

Smith. K. and Keenan, D.J. (2004) Smith and Keenan's English Law London: Pearson Education

Ware, N.C., Hopper, K., Tugenberg, T., Dickey, B. and Fisher, D. (2007) Connectedness and Citizenship. Psychiatirc Services, ps, psychiatryonline.org, 58 (4), pp 469- 474.

Westwood,J. (2003) The impact of adult education for mental health service users. British Journal of Occupational Therapy. 66(11), pp505-10.

Wilcock,A. (2006) An occupational perspective of health; Thofofare, NJ: Slack 
Wistow, R. and Scneider, J. (2003) Users' views on supported employment and social inclusion: a qualitative study of 30 people in work. British Journal of Learning Disabilities 31(4) pp 166-74.

Wolfensberger, W. (1980)The definition of normalization: update, problems, disagreements and misunderstandings. In Fylnn,R.J. and Nitsch,K.E. (eds) Normalization, Social Integration and Community Services, pp71-115. Balitmore: University Park Press.

Wolfensberger, W. (1995) Social Role Valorization is too conservative. No it is too radical. Disability and Society,10(3), pp245-7.

\section{Other sources}

http://ec.europa.eu/employment_social/spsi/docs/social_inclusion/approb_en.pdf (accessed 3112 07)

http://www.hpc-uk.org/ (accessed 2102 08)

http://www.ndt.org.uk/projectsN/SIPfeat.htm (accessed 2102 08)

http://www.qaa.ac.uk/academicinfrastructure/benchmark/health/ot (accessed 21 0208 )

https://wcd.coe.int/ViewDoc.jsp?id=1226267\& (accessed on 27.06.08)

http://www.who.int/classifications/icf/en/ (accessed 2106 08)

http://www.ndt.org.uk (accessed 2106 08)

http://ec.europa.eu/employment_social/spsi/docs/social_inclusion/2008/joint_rep ort_en.pdf (accessed 27.06.08) 